\title{
TiO2 Nanoparticles as Potential Promoting Agents of Fibrillation of a-Synuclein, a Parkinson's Disease-Related Protein
}

\author{
Soheila Mohammadi and Maryam Nikkhah*
}

Department of Nanobiotechnology, Faculty of Biological Sciences, Tarbiat Modares University, Tehran, 14115-175 Iran

*Corresponding author: Maryam Nikkhah, Department of Nanobiotechnology, Faculty of Biological Sciences, Tarbiat Modares University, Tehran, Iran. Tel: +98-21-82884734, Fax: +98-21-82884484, E-mail: m_nikkhah@modares.ac.ir

Received:13 March 2016; $\quad$ Revised:11 Sept.2016; $\quad$ Accepted: 20 June 2017； Published online: 19 August 2017

Background: In recent years, nanomaterials have been widely used in large quantities which make people be more frequently exposed to the chemically synthesized nanoparticles (NPs). When NPs are introduced into an organism, they may interact with a variety of cellular components with yet largely unknown pathological consequences.

Objective: It was found that NPs enhance the rate of protein fibrillation in the brain by decreasing the lag time for nucleation. Protein fibrillation is implicated in the pathogenesis of the several neurodegenerative diseases such as Parkinson's disease (PD). $\alpha$-Synuclein $(\alpha S)$ is natively an unfolded protein which is involved in the pathogenesis of PD. In the present study, we have analyzed the effects of three different NPs on $\alpha \mathrm{S}$ fibrillation.

Materials and Methods: $\alpha$ S protein expression and purification was done and fibrils formation was induced in the absence or presence of the three types of NPs (i. e., TiO2, SiO2, and $\mathrm{SnO} 2$ ). The enhancement of the fluorescence emission of Thioflavin T (ThT) and transmission electron microscopy (TEM) were used to monitor the appearance and growth of the fibrils. The adsorption of $\alpha \mathrm{S}$ monomers on the surface of NPs was investigated by tyrosine fluorescence emission measurements.

Results: We found that TiO2-NPs enhances $\alpha \mathrm{S}$ fibril formation even at a concentration of $5 \mu \mathrm{g} \cdot \mathrm{mL}^{-1}$, while the two other NPs show no significant effect on the kinetics of the fibrillation. Intrinsic tyrosine emission measurement has confirmed that the TiO2-NPs interact with $\alpha \mathrm{S}$ fibrillation products. It is suggested that TiO2NPs may enhance the nucleation of $\alpha \mathrm{S}$ protein that leads to protein fibril formation.

Conclusion: The fibrillization process of $\alpha \mathrm{S}$ protein is profoundly affected by the presence of TiO2-NPs. This finding unveils the neurotoxicity potential of the TiO2-NPs, which may be considered as a probable risk for PD.

Keywords: $\alpha$-Synuclein $(\alpha \mathrm{S})$; Nanoparticles (NPs); Parkinson's disease (PD); Titanium Dioxide Nanoparticles (TiO2-NPs)

\section{Background}

Nanoparticles (NPs) have existed in the environment since the beginning of the Earth's and its evolution. They are found naturally in the atmosphere, most natural waters, soils, and sediments (1). In recent years, nanomaterials have been widely used in the large quantities in consumer products, which makes people be frequently exposed to such particles (2). Also, with the advent of the nanoscience, there has been much interest about the ways through which NPs interact with the biological systems, due to their potential applications in different aspects of nanotechnology, and effects on human health $(3,4)$. However, few studies have dealt with the toxicological and environmental effects of the exposure to the nanomaterials; direct or indirect effects. Over the past two decades, there has been considerable research interest in the use of NPs in the study of protein and peptide aggregation, and amyloid-related diseases, as well. Amyloid fibrils consist of protein molecules folded into anti-parallel stacked cross- $\beta$ sheet structures, resulting in their anisotropic structure. When NPs are introduced in a living organism they may interact with a variety of cellular components with yet largely unknown pathological consequences. The influence of NPs on amyloid formation is of great interest due to their small sizes and high surface area- 
to-volume ratio. Targeting NPs dependent amyloid structure formation, the nucleation stage in this process is one of the most investigated ways for controlling or inducing this phenomenon (5). The observed effect of NPs on the nucleation phase is determined by the composition and the amount of particles as well as the nature of the particle's surface (6). Various thermodynamic parameters influence the interaction of proteins with the NPs in solution, regulate the protein assembly into fibrils, as well as disaggregation of the preformed fibrils (6).

A number of naturally occurring proteins play role in the fibrillar aggregation formation in body among which are Amyloid $\beta$ peptide in Alzheimer's disease (AD) (7), $\alpha \mathrm{S}$ in PD (8), huntingtin in Huntington's disease (9), amylin in type II diabetes, $\beta 2$-microglobulin in dialysis-related amyloidosis (10), and prion protein in bovine spongiform encephalopathy (11) is believed to play an important role in the pathogenesis of the mentioned clinical disorders.

The 140-residue $\alpha \mathrm{S}(14.4 \mathrm{kDa})$ is a presynaptic neuronal protein with an unknown normal function which its amyloidogenic propensity is associated with the several neurodegenerative disorders. These disorders include PD, multiple system atrophy, and dementia with Lewy bodies, collectively called synucleinopathies $(12,13)$, where $\alpha \mathrm{S}$ is the major fibrillar component of intracellular inclusions, also known as Lewy bodies and Lewy neuritis. In vitro studies have demonstrated that $\alpha \mathrm{S}$ can spontaneously form amyloid fibrils under typical physiological conditions (ionic strength, temperature, and $\mathrm{pH}$ ). The presence of foreign surfaces in the system, for instance in the form of engineered NPs, has been shown to profoundly affect the formation of amyloids (14-16).

As an example, Yanina et al. have shown that gold NPs induce a strong acceleration of $\alpha \mathrm{S}$ aggregation by influencing both the nucleation and growth phases of the overall pathway. The effects were observed to be dependent on the size and concentration of the NPs; being strongest for the $10 \mathrm{~nm}$ diameter NPs, which produced a 3-fold increase in the overall aggregation rate at concentrations as low as $20 \mathrm{nM}$ (17).

TiO2-NPs have been widely used in many daily products such as cosmetics, antiseptic agents, coating flux, water treatment chemicals, and photocatalysts etc. Uversky et al. have shown the association between exposure to heavy metals and an enhanced risk for developing PD (18). Several possible mechanisms have been proposed for metal-stimulated fibrillation of $\alpha \mathrm{S}$, the simplest of which would be involvement in the direct interactions between $\alpha \mathrm{S}$ and the metal, leading to the structural changes in $\alpha \mathrm{S}$ which result in its enhanced propensity toward aggregation. For instance, it has been reported that $\alpha \mathrm{S}$ aggregation is facilitated in the presence of $\mathrm{Cu}^{2+}(19)$ and $\mathrm{Al}^{3+}$ which induce structural perturbations in the protein (20). Thus, both environmental and other non-inherited factors may be responsible for the more common sporadic forms of the PD (21).

\section{Objectives}

While nanotechnology, production, and application of the nanoparticles are exponentially growing, the knowledge regarding the toxicological and environmental effects of the direct and indirect exposure to the nanomaterials is still in its early stages. In this study, we aimed to investigate the in vitro effects of the three different NPs (TiO2, $\mathrm{SiO} 2$, and $\mathrm{SnO} 2)$ on the fibrillation of the $\alpha \mathrm{S}$ protein; the major constituent of the protein clumps and the pathological hallmark of the PD.

\section{Materials and Methods}

\subsection{Materials}

TiO2-NPs, type P25, in anatase phase with the average primary particle size of $21 \pm 5 \mathrm{~nm}$, and $\mathrm{SiO} 2-\mathrm{NPs}$ were purchased from Plasmachem, Germany. SnO2-NPs were kindly gifted to us by Dr. S. Sadeghi (Department of chemistry, Tarbiat Modares University, Tehran, Iran). Kanamycin was obtained from Sigma-Aldrich Company (USA). Ni-NTA sepharose column was purchased from Qiagen (Germany).

\subsection{Expression and Purification of $\alpha S$}

For protein expression, the recombinant pNIC28Bsa4 vector containing $\alpha \mathrm{S}$ gene was transformed into E. coli C41 (DE3); starter cultures were prepared by inoculating a single colony of the bacteria to LB medium containing kanamycin $\left(50 \mu \mathrm{g} \cdot \mathrm{mL}^{-1}\right)$. After reaching to an of OD $600 \mathrm{~nm} 0.4$, IPTG $(0.1 \mathrm{mM})$ was added, and the culture was incubated for another 5 hours at $37^{\circ} \mathrm{C}$ (22). The induced cells were harvested by centrifugation at $5000 \times g$ for $15 \mathrm{~min}$. The cell pellet was resuspended in the lysis buffer $\left(50 \mathrm{mM} \mathrm{NaH}_{2} \mathrm{PO}_{4}, 300 \mathrm{mM} \mathrm{NaCl}\right.$, $10 \mathrm{mM}$ imidazole, $\mathrm{pH} 8$ ) and $1 \mathrm{mM}$ PMSF, and then cells were lysed by sonication on ice. The cell lysate was centrifuged at $16000 \times \mathrm{g}$ for $30 \mathrm{~min}$ at $4{ }^{\circ} \mathrm{C}$, the supernatant was applied to nickel-nitrilotriacetic acid (Ni-NTA) sepharose column (Qiagen, Germany), and the purification was done according to the manufacturer instructions (Qiagen, Inc. Germany). The purified protein was analyzed on $15 \%$ sodium dodecyl sulfatepolyacrylamide gel electrophoresis (SDS-PAGE). 


\subsection{Characterization of NPS}

The average particle size and Zeta potential of NPs were determined by Zetasizer Nano ZS instrument (Malvern Instruments, UK) at $25^{\circ} \mathrm{C}$. The NPs suspension was prepared by mixing the NPs with filtered PBS buffer (pH 7.4) and sonicating for $30 \mathrm{~min}$ at $600 \mathrm{~W}, 20 \mathrm{kHz}$.

\subsection{Fibrillation Experiment}

Purified $\alpha \mathrm{S}$ was dialyzed against sterile PBS buffer $(\mathrm{pH}$ 7.4) containing $0.02 \% \mathrm{NaN} 3$ as an antiseptic agent, and was immediately incubated at a final concentration of $35 \mu \mathrm{M}$, in the absence or presence of the different concentration of NPs at $37^{\circ} \mathrm{C}$ in a Turbo Thermo Shaker ( TMS-200, China) while shaking at $1000 \mathrm{rpm}$ for 100 hours. Fibrils formation was monitored by measuring the fluorescence enhancement of ThT (Sigma-Aldrich Company, USA). $10 \mu \mathrm{L}$ of each sample were taken at different time points and diluted with $100 \mu \mathrm{L}$ of PBS containing $25 \mu \mathrm{M}$ ThT to reach the final protein concentration of $3.5 \mu \mathrm{M}$. Fluorescence was measured in a clear black 96-well plate using a Cytation3 Cell Imaging Multi-Mode Reader (BioTek Instruments, Winooski, VT) with excitation wavelength at $440 \mathrm{~nm}$ and emission at $485 \mathrm{~nm}$. The samples were assayed in triplicates, and, each experiment was repeated at least three times.

\subsection{Fluorescence Titrations}

In order to analyze the interaction of $\alpha \mathrm{S}$ with NPs, the prepared $\alpha \mathrm{S}$ proteins at the concentration of 50 $\mu \mathrm{M}$ and $35 \mu \mathrm{M}$ were mixed with NPs $\left(50 \mu \mathrm{g} \cdot \mathrm{mL}^{-1}\right)$ and fluorescence spectra were collected using a spectrofluorimeter (Perkin-Elmer model LS 50B). An excitation wavelength of $280 \mathrm{~nm}$ (slit width $=5 \mathrm{~nm}$ ) was used and the data were collected over the range width of 290-350 $\mathrm{nm}$ (slit width $=5 \mathrm{~nm}$ ).

\subsection{Transmission Electron Microscopy (TEM) Analysis} Aliquotes $(10 \mu \mathrm{L})$ from the $\alpha \mathrm{S}$ fibrillation reaction (with and without TiO2-NPs) were placed on formvar/ carbon-coated 300- mesh grids. After 2 minutes, excess fluid was removed, and the grids were negatively stained with $1 \%$ uranyl acetate solution for 2 minutes. Finally, excess fluid was removed and the samples were viewed by a Zeiss - EM10C - $80 \mathrm{KV}$ TEM.

\section{Results}

\section{1. $\alpha S$ Protein Expression and Purification}

Transformation of the plasmid pNIC28-Bsa4 $\alpha \mathrm{S}$ resulted in the high level expression of $\alpha \mathrm{S}$ protein after 5 hours of the induction of the protein expression. The protein was purified by one step metal affinity chromatography and analyzed by gel electrophoresis. While the molecular weight of the protein was estimated to be $16.4 \mathrm{kDa}$, SDS-PAGE analysis of the purified protein showed a band with a molecular weight of more than $17 \mathrm{kDa}$ (Fig. 1). The
A

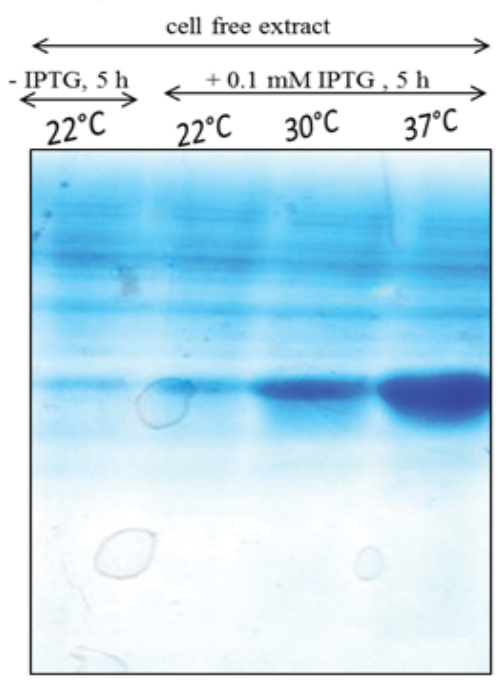

B

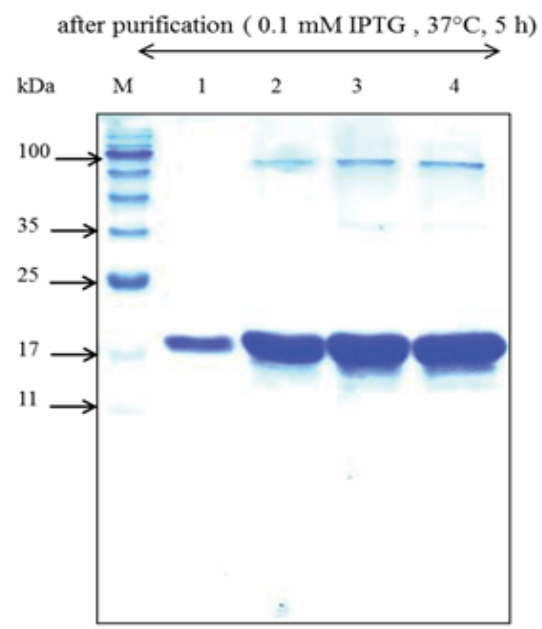

Figure 1. SDS-PAGE analysis of A) soluble fractions of the bacterial extracts with and without induction by IPTG at different temperatures and B) the purified recombinant $\alpha$ S protein using Ni-NTA sepharose column. Four samples with increasing protein concentrations were run in parallel with the molecular mass standards on a $15 \%$ polyacrylamide gel and stained with Coomassie Blue R-250. The molecular weight of the marker proteins is shown as $\mathrm{M}$ lane in gel $\mathrm{B}$, the first lane from the left. 
Mohammadi S \& Nikkhah M

Table 1. The average size and the Zeta potential of the colloidal solutions of the different NPs.

\begin{tabular}{llll}
\hline Type of NPs & Average size $(\mathbf{d} . \mathbf{n m})$ & Zeta potential $(\mathbf{m V})$ & PdI \\
\hline TiO2-NPs & 91.35 & -11.9 & 0.178 \\
SiO2- NPs & 69.2 & -18.3 & 0.621 \\
SnO2- NPs & 278 & -17.6 & 0.639 \\
\hline
\end{tabular}

slow mobility of $\alpha \mathrm{S}$ protein can be attributed to the low binding of the SDS to the highly acidic C-terminal sequence of $\alpha \mathrm{S}(23)$.

\subsection{Characterization of NPs}

The NPs were well suspended in PBS buffer ( $\mathrm{pH} 7.4)$ by means of sonication. The size and Zeta potential of the nanoparticles have been shown in Table 1.

\subsection{TiO2-NPs Promote $\alpha S$ Fibrillation}

Fibrillation of $\alpha \mathrm{S}$ is a two-step process: an initial lag period that reflects the thermodynamic barrier to the formation of a nucleation "seed", followed by the rapid fibril propagation and aggregation formation stage. The introduction of TiO2-NPs in $\alpha \mathrm{S}$ aggregation reaction substantially decreased the lag time (Fig. 2A) and significantly enhanced $\alpha \mathrm{S}$ aggregation as monitored by ThT fluorescence measurements (Fig. 2B). This indicates that the TiO2-NPs are able to enhance the nucleus formation. This effect is dependent on the concentration of the TiO2-NPs as checked for 5, 25, and $50 \mu \mathrm{g} . \mathrm{mL}^{-1}$ of the NPs (Fig. 3). However, the kinetics of $\alpha \mathrm{S}$ fibrillation was not altered by $\mathrm{SiO} 2$, and $\mathrm{SnO} 2-\mathrm{NPs}$ (Fig. 2A).

\subsection{The Interaction of TiO2-NPs and $\alpha$ S Fibrillation Products}

To analyze the conformational changes exerted by $\alpha \mathrm{S}$ adsorption on the surface of TiO2-NPs, tyrosine fluorescence emission spectra of the protein in the presence of different NPs were acquired (there isn't a tryptophan residue in $\alpha \mathrm{S}$ ). It has been suggested that NPs can interact with protein monomers, eventually leading to a locally high concentration of monomers on the surface of the NPs, and in turn facilitate the nucleation and the fibrillation process (5). In this study, tyrosine fluorescence emission spectra of $\alpha \mathrm{S}$ were acquired in the presence of different NPs. Interestingly, all NPs showed the quenching effect on the intrinsic fluorescence of $\alpha \mathrm{S}$, and all the examined NPs have induced structural change to some extent in $\alpha \mathrm{S}$, however, the effect of TiO2-NPs was more prominent than the other NPs (Fig. 4).

The higher quenching effect of TiO2-NPs may implicate the better adsorption of $\alpha \mathrm{S}$ protein on the surface of TiO2-NPs. It could be suggested that TiO2-NPs can adsorb $\alpha \mathrm{S}$ onto their surfaces and provide a locally high concentration of $\alpha \mathrm{S}$ monomers, which may explain the promoting effect of TiO2-NPs on $\alpha \mathrm{S}$ fibrillation.
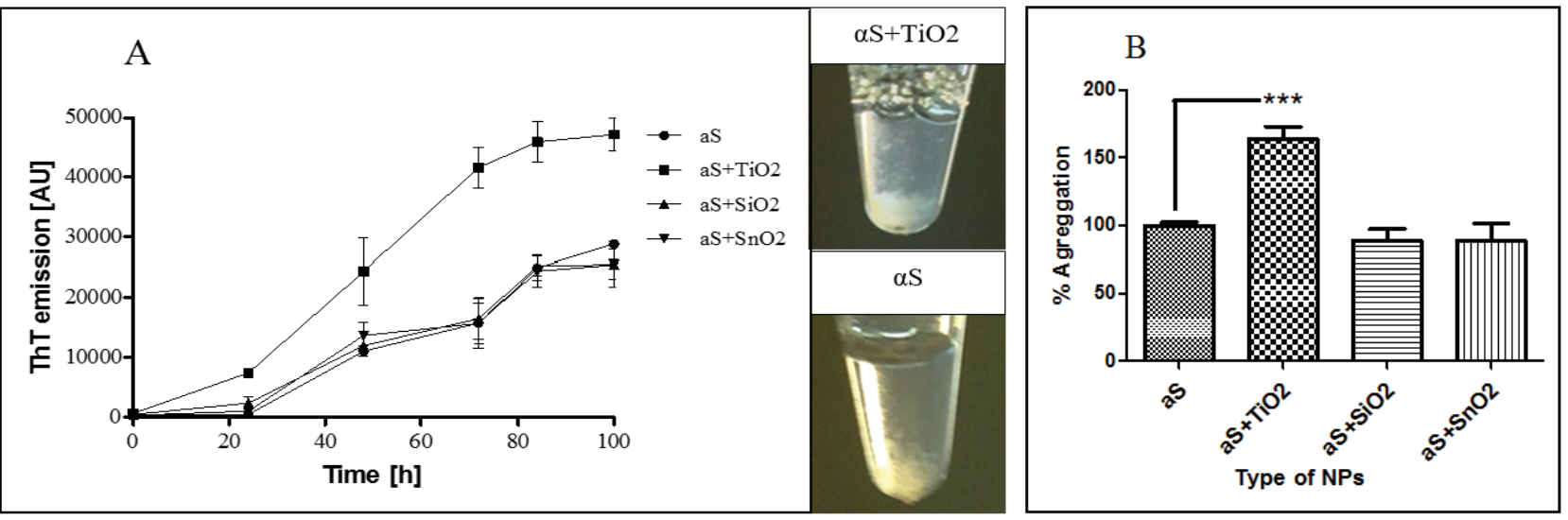

Figure 2. A) Kinetics of $\alpha \mathrm{S}$ fibrillation in the presence of different NPs. ThT fluorescence was plotted as a function of time for $35 \mu \mathrm{M} \alpha \mathrm{S}$ at $37^{\circ} \mathrm{C}$ in PBS (pH 7.4) without or with $50 \mu$ g.mL $\mathrm{mL}^{-1}$ of NPs. The NPs include TiO2, $\mathrm{SiO} 2$, and $\mathrm{SnO} 2$. The values are means $\pm \mathrm{SD}, \mathrm{n}=3$. B) The percentage of $\alpha \mathrm{S}$ aggregation in the presence of different $\mathrm{NPs}\left(50 \mu \mathrm{g} \cdot \mathrm{mL}^{-1}\right)$ compared to the control $(\alpha \mathrm{S})$ after 100 hours of incubation under an aggregation inducing conditions. Each experiment was conducted three times. ${ }^{*} \mathrm{p}<0-05 ; * * \mathrm{p}<0.01 ; * * * \mathrm{p}<0.001$, one-way ANOVA and LSD's post-hoc test. 


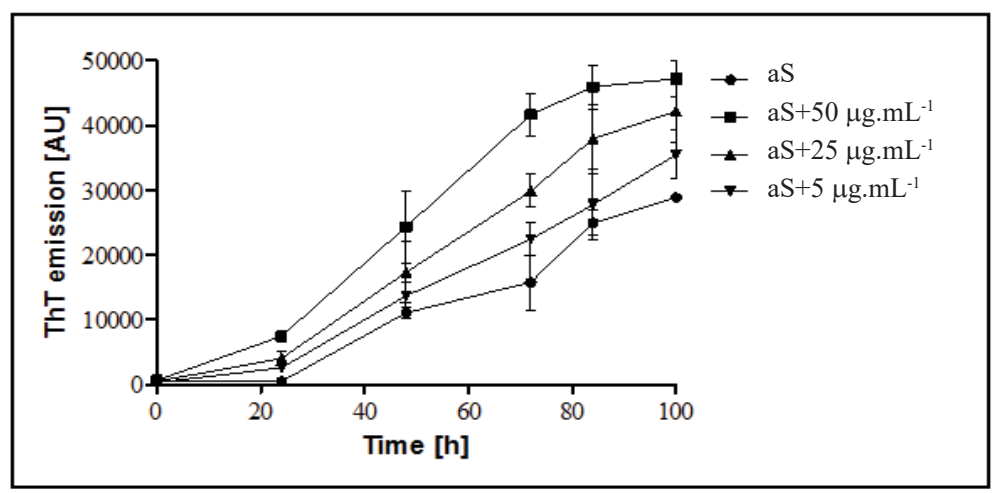

Figure 3. Kinetics of the $\alpha \mathrm{S}$ fibrillation in the presence of different concentration of TiO2-NPs . ThT fluorescence was plotted as a function of time for $35 \mu \mathrm{M} \alpha \mathrm{S}$ at $37{ }^{\circ} \mathrm{C}$ in PBS (pH 7.4). The values represent the means obtained for 3 separate experiments $(n=3)$ and $\pm S D$.

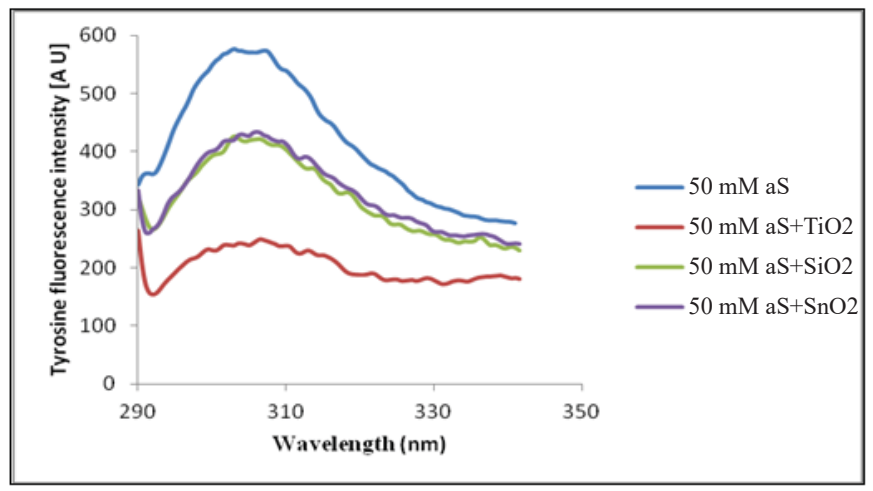

Figure 4. Tyrosine fluorescence signal of $\alpha \mathrm{S}$ in the presence of the different applied NPs.

4.5. TEM Analysis of $\alpha S$ Fibril Formation in the Presence of TiO2-NPS

TEM analysis was performed on the samples of $\alpha \mathrm{S}$ incubated under the amyloid-inducing conditions (alone or in the presence of the TiO2-NPs), to confirm the formation of $\alpha \mathrm{S}$ amyloid fibrils and to explore the ultrastructure of the aggregates. Samples were taken from the aggregation reactions after 100 hours. Consistent with the results of ThT experiments, TEM analysis has also confirmed the formation of amyloid fibrils in both the $\alpha \mathrm{S}$ and $\alpha \mathrm{S}$ supplemented with $\mathrm{TiO} 2$ nanoparticles samples (Fig. 5). A higher amount of amyloid fibrils formation could be seen in the presence of $\mathrm{TiO} 2$ nanoparticles as shown in Figure 5.

\section{Discussion}

In brief, this study has investigated the effect of $\mathrm{TiO} 2$, $\mathrm{SiO} 2$, and $\mathrm{SnO} 2-\mathrm{NPs}$ on $\alpha \mathrm{S}$ protein aggregation. Here we have shown that TiO2-NPs might be one of the environmental factors involved in PD. We found that TiO2-NPs are able to promote $\alpha \mathrm{S}$ assembly into amyloid fibrils in vitro by presumably accelerating the nucleation process. This feature could result from a locally high $\alpha \mathrm{S}$ monomer concentration owing to the adsorption on the TiO2-NPs surface. These results unveil the potential neurotoxicity of TiO2-NPs exposure, which may cause PD.

Based on previous reports regarding neurotoxicity of the ferrous oxide and silicon dioxide $(24,25)$, recently Jie Wu et al. (21) have investigated the effects of TiO2NPs on $\alpha \mathrm{S}$ aggregation and explored the mechanism of NPs action by establishing a co-culture model of TiO2NPs and dopaminergic neurons. It has been shown that TiO2-NPs could induce PD-related $\alpha \mathrm{S}$ protein aggregation through oxidative stress, thus causing damage to the dopaminergic neurons and subsequently PD. Jie Wu et al. (25) have also demonstrated that SiO2-NPs could possibly have a negative impact on the striatum and dopaminergic neurons as well as a potential risk for neurodegenerative diseases, which is in contrast to the results of the present study in which an effect on $\alpha \mathrm{S}$ assembly into amyloid fibrils was not observed in the presence of SiO2-NPs. The acceleration of $\alpha \mathrm{S}$ fibrillation in the presence of $\alpha \mathrm{S}$-conjugated $\mathrm{CdSe} / \mathrm{ZnS}$ quantum dots has been reported by the Roberti et al. (26). In addition, Yang et al. $(27,28)$ have 

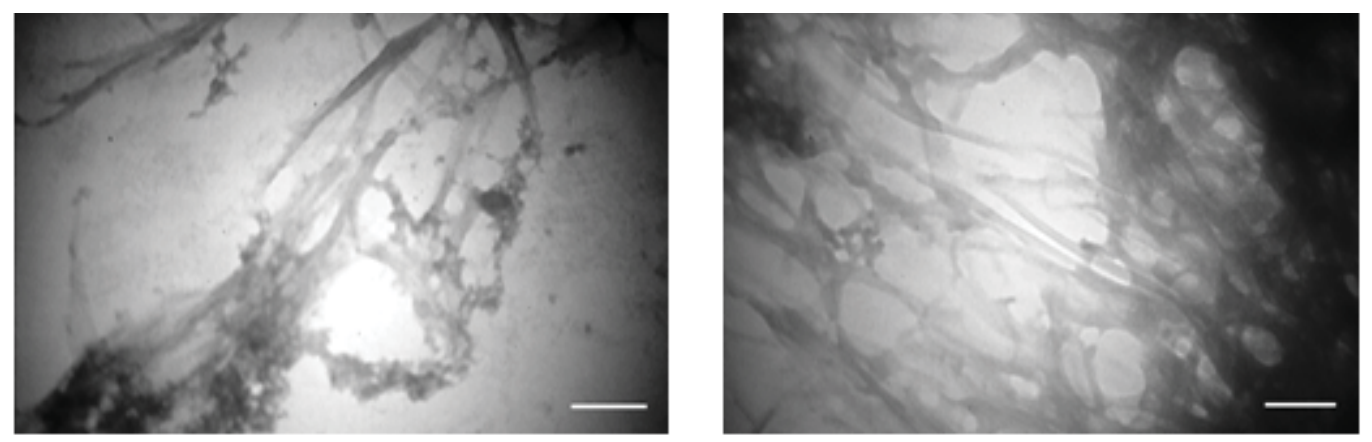

Figure 5. TEM micrographs of the samples taken from the $\alpha \mathrm{S}$ fibrillation reaction. $\alpha \mathrm{S}$ protein was incubated without (left) TiO2-NPs or with $50 \mu \mathrm{g} \cdot \mathrm{mL}^{-1}$ of TiO2-NPs under amyloid inducing conditions for $100 \mathrm{~h}$ (scale bar represents $120 \mathrm{~nm}$ for both micrographs).

studied the interaction of the $\alpha \mathrm{S}$ with both negative and positively charged gold NPs and have proven a large conformational change of $\alpha \mathrm{S}$ upon interaction with the gold nanoparticles.

Linse et al. (29) have found that all $\mathrm{TiO} 2, \mathrm{SiO} 2$, $\mathrm{ZrO} 2, \mathrm{CeO} 2, \mathrm{C} 60$, and $\mathrm{C} 70 \mathrm{NPs}$ can promote $\beta 2-$ Microglobulin fibrillation in vitro. They observed that the duration of the lag phase depends on the amount and the nature of the particle surface. Wei-hui Wu et al. (30) have shown that all six kinds of the abovementioned NPs can bind to $\mathrm{A} \beta 42$, but only $\mathrm{TiO} 2$ can strongly be adsorbed to the $A \beta$ protein and influence the fibrillation process. The difference between the Linse's results with that of Wei-hui Wu may be correlated to the differences that the two proteins might have in their fibril formation capacity. $A \beta 42$ has a strong tendency to form a nuclear seed (31) while $\beta 2$-Microglobulin is relatively more resistant to fibril formation, and therefore any weak adsorption of the proteins on the surface of the nanoparticles may be important for shortening the lag time.

Colvin et al. (32) have proposed that NPs may act much like conventional catalysts in promoting fibrillation. NPs would reduce the energetic barriers for fibril formation by enhancing the population of prefibril aggregates. Although the detailed molecular mechanism of the nucleation on the NPs surface remains elusive, but it could involve by mean of establishing a higher concentration of monomers which in turn increase the probability of the nucleation events. Alternatively, the interaction with particle surfaces could actively promote a conformational change and consequently the aggregation of the protein (33). Nonetheless, the dependence of the lag phase length on the accessible surface area and its characteristics (relative hydrophobicity) suggest that the nucleation mechanism involves association of the protein with the particle surface. This effect has been studied by using surface plasmon resonance (SPR) (29).

Herein, it was demonstrated that $\mathrm{TiO} 2-\mathrm{NPs}$ interact more strongly with $\alpha \mathrm{S}$ than $\mathrm{SiO} 2$ and $\mathrm{SnO} 2-\mathrm{NPs}$, (Fig. 4). This interaction caused a significant change in the conformation of $\alpha \mathrm{S}$, which led to the exposure of the hydrophobic regions of the protein to the solvent and hence presumably increased the occurrence of the nucleation events.

Overall, it seems that the control of amyloid formation via NPs can be explained based on two factors: first, the surface chemistry of NPs, and the second, the protein's intrinsic stability. These factors determine the interaction between NPs and the proteins or peptides, and hence, they may act either as a platform for nucleation or as destabilizing agents, causing acceleration of amyloid formation (14).

Studies have shown that many NPs are small enough to access all parts of the body including the brain (34). The invasion of the nanomaterial into the brain, especially the NPs with a strong ability to promote $\alpha \mathrm{S}$ fibrillation, may be an important environmental factor in the pathogenesis of PD. These findings also suggest other more positive future directions in which NPs could be used to form new protein assemblies or to enhance and control the rate of protein or peptide self-assembly into amyloid-like materials with novel biotechnological properties and applications.

\section{Conclusion}

The pathogenesis of PD is associated with $\alpha \mathrm{S}$ fibrillation. There is limited data on the interaction of $\alpha \mathrm{S}$ with NPs and their effects on its aggregation kinetics. In this study, we surveyed the effect of three different NPs on $\alpha \mathrm{S}$ fibrillation and found that TiO2-NPs can promote $\alpha \mathrm{S}$ fibrillation by shortening the nucleation process, which is the key rate determining step of $\alpha \mathrm{S}$ fibrillation. Hereby, we suggest that the interaction between $\alpha \mathrm{S}$ and TiO2-NPs may contribute to the PD etiology. 
Nanotechnology offers great promises in many industrial applications. It is necessary to control and prevent the unwitting use of potentially hazardous nanomaterials. To keep PD away from human beings, the potential of NPs and nanomaterials hazards should be seriously taken into account and be eliminated.

\section{Acknowledgements}

Financial support of this work was provided by Research Council of Tarbiat Modares University of Iran.

\section{References}

1. Crane M, Handy RD, Garrod J, Owen R. Ecotoxicity test methods and environmental hazard assessment for engineered nanoparticles. Ecotoxicology. 2008;17(5):421-37. DOI: 10.1007/s10646-008-0215-z.

2. Colvin VL. The potential environmental impact of engineered nanomaterials. Nature Biotechnol. 2003;21(10):1166-70. DOI: $10.1038 /$ nbt875.

3. Lewinski N, Colvin V, Drezek R. Cytotoxicity of nanoparticles. small. 2008;4(1):26-49. DOI: 10.1002/smll.200700595.

4. Sanvicens N, Marco MP. Multifunctional nanoparticlesproperties and prospects for their use in human medicine. Trends Biotechnol. 2008;26(8):425-33. DOI: 10.1016/j. tibtech.2008.04.005.

5. Auer S, Trovato A, Vendruscolo M. A condensation-ordering mechanism in nanoparticle-catalyzed peptide aggregation. PLoS Comput Biol. 2009;5(8):e1000458. DOI: 10.1371/journal. pcbi.1000458.

6. Zaman M, Ahmad E, Qadeer A, Rabbani G, Khan RH. Nanoparticles in relation to peptide and protein aggregation. Int J Nanomedicine. 2014;9:899. DOI: 10.2147/IJN.S54171.

7. Hardy J, Selkoe DJ. The amyloid hypothesis of Alzheimer's disease: progress and problems on the road to therapeutics. Science. 2002;297(5580):353-6. DOI: 10.1126/ science. 1072994.

8. George JM. The synucleins. Genome Biol. 2002;3(1):3002.1-.6.

9. Díaz-Hernández M, Moreno-Herrero F, Gómez-Ramos P, Morán MA, Ferrer I, Baró AM, et al. Biochemical, ultrastructural, and reversibility studies on huntingtin filaments isolated from mouse and human brain. $J$ Neurosci. 2004;24(42):9361-71. DOI: 10.1523/JNEUROSCI.2365-04.2004.

10. Radford SE, Gosal WS, Platt GW. Towards an understanding of the structural molecular mechanism of $\beta$ 2-microglobulin amyloid formation in vitro. Biochim Biophys Acta. 2005;1753(1):51-63. DOI: 10.1016/j.bbapap.2005.07.006.

11. Jones EM, Surewicz WK. Fibril conformation as the basis of species-and strain-dependent seeding specificity of mammalian prion amyloids. Cell. 2005;121(1):63-72. DOI: 10.1016/j. cell.2005.01.034.

12. Uversky VN. Neuropathology, biochemistry, and biophysics of $\alpha$-synuclein aggregation. $J$ Neurochem. 2007;103(1):17-37. DOI: $10.1111 / \mathrm{j} .1471-4159.2007 .04764 . x$.

13. Goedert M, Spillantini MG, Davies SW. Filamentous nerve cell inclusions in neurodegenerative diseases. Curr Opin Neurobiol. 1998;8(5):619-32. DOI: 10.1016/S0959-4388(98)80090-1.

14. Cabaleiro-Lago C, Quinlan-Pluck F, Lynch I, Lindman S, Minogue AM, Thulin E, et al. Inhibition of amyloid $\beta$ protein fibrillation by polymeric nanoparticles. $J$ Am Chem Soc. 2008;130(46):15437-43. DOI: 10.1021/ja8041806.

15. Giacomelli CE, Norde W. Influence of hydrophobic Teflon particles on the structure of amyloid $\beta$-peptide. Biomacromolecules. 2003;4(6):1719-26. DOI: 10.1021/ bm034151g.

16. Rocha $\mathrm{S}$, Thünemann $\mathrm{AF}$, do Carmo Pereira $\mathrm{M}$, Coelho $\mathrm{M}$, Möhwald H, Brezesinski G. Influence of fluorinated and hydrogenated nanoparticles on the structure and fibrillogenesis of amyloid beta-peptide. Biophys Chem. 2008;137(1):35-42. DOI: 10.1016/j.bpc.2008.06.010.

17. Álvarez YD, Fauerbach JA, Pellegrotti JV, Jovin TM, JaresErijman EA, Stefani FD. Influence of gold nanoparticles on the kinetics of $\alpha$-synuclein aggregation. Nano Lett. 2013;13(12):6156-63. DOI: 10.1021/n1403490e.

18. Uversky VN, Li J, Fink AL. Metal-triggered Structural Transformations, Aggregation, and Fibrillation of Human $\alpha$-Synuclein. A possible molecular NK between Parkinson's disease and heavy metal exposure. J Biol Chem. 2001;276(47):44284-96. DOI: 10.1074/jbc.M105343200.

19. Paik SR, Shin H-J, Lee J-H. Metal-catalyzed oxidation of $\alpha$-synuclein in the presence of copper (II) and hydrogen peroxide. Arch Biochem Biophys. 2000;378(2):269-77. DOI: 10.1006/abbi.2000.1822.

20. Paik SR, Lee J-H, Kim D-H, Chang C-S, Kim J. Aluminuminduced structural alterations of the precursor of the non-A $\beta$ component of Alzheimer's disease amyloid. Arch Biochem Biophys. 1997;344(2):325-34. DOI: 10.1006/abbi.1997.0207.

21. $\mathrm{Wu} \mathrm{J}$, Xie H. Effects of titanium dioxide nanoparticles on $\alpha$-synuclein aggregation and the ubiquitin-proteasome system in dopaminergic neurons. Artif Cells Nanomed Biotechnol. 2016;44(2):690-4. DOI: 10.3109/21691401.2014.980507.

22. Caldinelli L, Albani D, Pollegioni L. One single method to produce native and Tat-fused recombinant human $\alpha$-synuclein in Escherichia coli. BMC Biotechnol. 2013;13(1):32. DOI: 10.1186/1472-6750-13-32.

23. Weinreb PH, Zhen W, Poon AW, Conway KA, Lansbury PT. NACP, a protein implicated in Alzheimer's disease and learning, is natively unfolded. Biochemistry. 1996;35(43):13709-15. DOI: $10.1021 /$ bi961799n.

24. Pisanic TR, Blackwell JD, Shubayev VI, Fiñones RR, Jin S. Nanotoxicity of iron oxide nanoparticle internalization in growing neurons. Biomaterials. 2007;28(16):2572-81. DOI: 10.1016/j.biomaterials.2007.01.043.

25. Wu J, Wang C, Sun J, Xue Y. Neurotoxicity of silica nanoparticles: brain localization and dopaminergic neurons damage pathways. A C S Nano. 2011;5(6):4476-89. DOI: 10.1021/nn103530b.

26. Roberti MJ, Morgan M, Menéndez G, Pietrasanta LI, Jovin TM, Jares-Erijman EA. Quantum dots as ultrasensitive nanoactuators and sensors of amyloid aggregation in live cells. $\mathrm{J} \mathrm{Am} \mathrm{Chem}$ Soc. 2009;131(23):8102-7. DOI: 10.1021/ja900225w.

27. Yang JA, Lin W, Woods WS, George JM, Murphy CJ. $\alpha$-Synuclein's Adsorption, Conformation, and Orientation on Cationic Gold Nanoparticle Surfaces Seeds Global Conformation Change. J Phys Chem B. 2014;118(13):3559-71. DOI: $10.1021 / \mathrm{jp} 501114 \mathrm{~h}$.

28. Yang JA, Johnson BJ, Wu S, Woods WS, George JM, Murphy CJ. Study of wild-type $\alpha$-synuclein binding and orientation on gold nanoparticles. Langmuir. 2013;29(14):4603-15. DOI: 10.1021/la400266u.

29. Linse S, Cabaleiro-Lago C, Xue W-F, Lynch I, Lindman 
$\mathrm{S}$, Thulin E, et al. Nucleation of protein fibrillation by nanoparticles. Proc Natl Acad Sci. 2007;104(21):8691-6. DOI: 10.1073/pnas.0701250104.

30. Wu W-h, Sun X, Yu Y-p, Hu J, Zhao L, Liu Q, et al. TiO 2 nanoparticles promote $\beta$-amyloid fibrillation in vitro. Biochem Biophys Res Commun. 2008;373(2):315-8. DOI: 10.1016/j. bbrc.2008.06.035.

31. Harper JD, Lansbury Jr PT. Models of amyloid seeding in Alzheimer's disease and scrapie: mechanistic truths and physiological consequences of the time-dependent solubility of amyloid proteins. Annu Rev Biochem. 1997;66(1):385-407. DOI: 10.1146/annurev.biochem.66.1.385.

32. Colvin VL, Kulinowski KM. Nanoparticles as catalysts for protein fibrillation. Proc Natl Acad Sci. 2007;104(21):8679-80. DOI: $10.1073 /$ pnas.0703194104.

33. Mohammad-Beigi H, Shojaosadati SA, Marvian AT, Pedersen JN, Klausen LH, Christiansen G, et al. Strong interactions with polyethylenimine-coated human serum albumin nanoparticles (PEI-HSA NPs) alter $\alpha$-synuclein conformation and aggregation kinetics. Nanoscale. 2015;7(46):19627-40. DOI: 10.1039/ C5NR05663B.

34. Oberdörster G, Sharp Z, Atudorei V, Elder A, Gelein R, Kreyling W, et al. Translocation of inhaled ultrafine particles to the brain. Inhal Toxicol. 2004;16(6-7):437-45. DOI: 10.1080/08958370490439597. 